\title{
Association of ficolin-2 (FCN2) functional polymorphisms and protein levels with rheumatic fever and rheumatic heart disease: relationship with cardiac function
}

Manal F. Elshamaa ${ }^{1}$, Hala Hamza², Naglaa Abd El Rahman², Soha Emam², Eman A. Elghoroury³, Tarek M. Farid ${ }^{1}$, Asmaa Zakareya Zaher ${ }^{2}$, Mona H. Ibrahim³ ${ }^{3}$, Solaf Kamel'3 , Doaa Abd El-Aziz²

${ }^{1}$ Pediatrics Department, National Research Centre (NRC), Cairo, Egypt

${ }^{2}$ Pediatrics Department, Faculty of Medicine, Cairo University, Cairo, Egypt

${ }^{3}$ Clinical and Chemical Pathology Department, National Research Centre, Cairo, Egypt

Submitted: 25 April 2018

Accepted: 4 October 2018

Arch Med Sci Atheroscler Dis 2018; 3: e142-e155

DOI: https://doi.org/10.5114/amsad.2018.80999

Copyright (c) 2018 Termedia \& Banach

\section{Abstract}

Introduction: A role for ficolin (FCN) 2 gene polymorphisms in the pathogenesis of recurrent severe streptococcal infections and rheumatic carditis has been suggested. The aim of the study was to evaluate a possible relationship between single nucleotide polymorphisms located at positions - 602 and -4 of the FCN2 gene and FCN2 serum levels and risk of development of rheumatic fever (RF) and rheumatic heart disease (RHD).

Material and methods: Seventy-seven Caucasian Egyptian patients with RF were recruited with a control group of 43 healthy subjects. DNA was extracted for analysis of the FCN2 gene at positions -602 and -4 and serum protein level was measured by ELISA.

Results: FCN2 AA genotype at the -4 position was more frequently observed in RF and RHD patients, as compared to healthy subjects ( $p=0.005$ and $p=0.013$, respectively); furthermore, the A allele was identified as a possible risk factor for the development of $\operatorname{RF}(p=0.023, \mathrm{OR}=1.852,95 \% \mathrm{Cl}$ : 1.085-3.159). The haplotype $-602 /-4 G / A$, which was associated with low median levels of L-ficolin, was observed more frequently in the RF group when compared to the healthy subjects $(74 / 162,48.1 \%$ vs. $29 / 420,33.7 \%$, $\mathrm{OR}=1.834,95 \% \mathrm{Cl}: 1.034-3.252, p=0.038)$. Low serum ficolin-2 level was associated with ESV and EDV increases. FCN 2 level was significantly lower with AA genotypes than GG+AG genotypes of the -4 position $(56.68 \pm 17.90$ vs. $66.05 \pm 18.79, p=0.008$ ).

Conclusions: Polymorphisms linked to low levels of L-ficolin may render an individual at risk of recurrent and/or severe streptococcal infection. The -4 AA genotype and -602/-4 G/A haplotype are possible risk factors for the development of carditis.

Key words: rheumatic fever, rheumatic heart disease, L-ficolin (ficolin-2), FCN2 gene, polymorphism.

\section{Introduction}

Rheumatic fever (RF) and its most severe consequence chronic rheumatic heart disease (RHD) are chronic inflammations that accompany group AB-hemolytic Streptococcus oropharynx infection. The disease occurs in children and teenagers who are genetically predisposed (aged 3-19 years) causing multi-organ effects [1]. The onset of RF usually hap-

\section{Corresponding author:} Manal Fouad Elshamaa Pediatrics Department Research Institute National Research Centre 33 Elbohous St Dokki, Cairo, Egypt Phone: +20 233371010 Fax: +20 237601877 E-mail:manal_elshmaa@ hotmail.com 
pens 2 to 3 weeks after the initial pharyngitis, but in some situations the onset may be months afterwards [2]. Though arthritis is the utmost common symptom of RF, affecting $75 \%$ of affected children, the most severe clinical symptom is carditis, affecting about $30-50 \%$ of children after the first RF episode by 4-8 weeks [3]. Broadly, carditis may be complicated by permanent valvular damage in $30-50 \%$ of the affected individuals as it is accompanied with chronic inflammation and valve tissue stenosis [4]. This chronic carditis is as yet the main cause of acquired cardiac valvulopathy [4].

Rheumatic heart disease affects young adults and remains a major public health problem due to high morbidity and mortality in Egypt and other developing countries. The incidence of RF exceeds 50 per 100,000 children in some developing countries with some of the highest rates reported in Indigenous Australians at 153 to 380 cases per 100,000 children aged 5 to 14 years [5]. Rheumatic heart disease global prevalence varies between 15 and 20 million patients with 470,000 new cases and 275,000 deaths annually [6]. A required repeated hospitalization is needed for about two million patients and one million may require a heart transplant in 5-20 years, causing high expenditure for the health system $[1,6,7]$.

The RF and RHD are complicated diseases with underlying multifactorial elements. Environmental as well as genetic factors are implicated in its pathogenesis [8]. The complement system upholds the adaptive immune system in gaining momentum to react and acts as the backbone of innate immunity. Presently, more than 40 components of the complement system have been demonstrated [9]. Three pathways activate the complement system: the classical, alternative (AP) and lectin pathways. Complement activation leads to pathogen destruction, clearance of immune complexes and apoptotic cells and induction of inflammatory mediators [10, 11]. The initiation of the lectin pathway is triggered by binding of mannose-binding lectin (MBL) or ficolins (FCNs) to carbohydrates or acetylated residues on the surface of pathogens, respectively [11]. The formation of C3 convertase is activated by serine proteases named MBL-associated serine proteases 1 and 2 (MASP-1 and MASP-2) accompanying MBL and ficolins [12].

Ficolins are pattern-recognition proteins (PRPs) involved in the innate immune response. Ficolins combine with specified pathogen-associated molecular patterns (PAMPs) on surfaces of microorganisms, stimulating the innate immune response by either combining or initiating the complement lectin pathway or collectin cellular receptors [13]. The ficolins are synthesized as a single polypeptide containing $\mathrm{N}$-collagen-like and C-terminal fibrino- gen-like sugar binding domains, which are oligomerized into higher oligomeric forms [13]. Both ficolin- 2 and ficolin-3 react with the MBL-associated serine proteases, allowing subsequent activation of a cascade of complement proteins [14]. Other roles of ficolins involve combining to apoptotic bodies, late apoptotic cells and necrotic cells accelerating their phagocytosis by macrophages [15]. Lipoteichoic acid, a cell wall constituent of all Gram-positive bacteria, is a major target for ficolin-2, and thereby activates the lectin pathway of complement. Ficolin-2 was demonstrated to combine with various pathogens of clinical relevance, such as S. agalactiae and S. pyogenes $[16,17]$.

In humans, ficolin genes are three in number, namely FCN1, FCN2 and FCN3, which encode, respectively, ficolin-1 (M-ficolin), ficolin-2 (L-ficolin) and ficolin-3 (H-ficolin) [18]. The three genes are quiet different in their action, sequence and cell specificity. Several single nucleotide polymorphisms (SNPs) in the promoter regions of the FCN2 gene as well as in exons 3, 6 and 8 have been described $[18,19]$. Changes in serum ficolin-2 concentrations have been linked to FCN2 promoter polymorphisms -602 and -4, whereas increased or decreased capability of carbohydrate combining was attributed to polymorphisms located in exon 8 , encoding the fibrinogen-like domain (+6359 and $+6424)[18,20,21]$. The occurrence of the nucleotide adenine (A) at positions -986 and -602 seems to favor high ficolin-2 serum levels $(A / A>A / G>$ $G / G)$ as well as the nucleotide guanine $(G)$ at the position $-4(G / G>G / A>A / A)$ [13]. In previous studies, an association between haplotypes/genotypes related to higher expression of serum levels of MBL, with acute and chronic rheumatic carditis, has been demonstrated $[22,23]$. In this study we searched for a possible relationship between single nucleotide polymorphisms located at positions -602 , and -4 of the promoter region of the FCN2 gene (their genotypes and haplotypes) and FCN2 serum levels with susceptibility to RF and RHD.

\section{Material and methods}

This retrospective case-control study was approved by the local ethics committee of the National Research Centre (NRC) in Egypt and ethical committee of the Pediatric Department, Cairo University, and informed consent for genetic studies was obtained from patients or parents of participants. We investigated a total of 77 patients with a history of RF and diagnosed according to Jones' modified criteria [24]. They were out-patients attending the Cardiology Clinic of Cairo University, Specialized Pediatric Hospital, Cairo University and from the Cardiology Out-patient Clinic of the Medical Research Centre of Excellence (MRCE) at NRC, Egypt. Their mean age was $14.54 \pm 4.67$ (range: $4-28$ years). 
Rheumatic valvular disease was confirmed based on the clinical history as well as on transthoracic echocardiograms of all the patients. Sixty-two (80.52\%) had RHD, confirmed by the transthoracic echocardiogram showing rheumatic involvement of the mitral valve; 15 (19.48\%) patients did not have RHD but had a history of RF and were designated as "rheumatic fever only" (RFo) patients. None of the patients presented other inflammatory disease, neoplasia, infective endocarditis or other infection at the time of blood collection. Among the patients with RHD, 4 (5.19\%) had undergone a previous surgical intervention due to rheumatic etiology (biological valve: Ross operation 1, mitral valve repair 1 and metal valve 2 ) and 73 (94.81\%) had not undergone any invasive procedure until the time of the study. Further clinical features of the patients with RF and RHD are presented in Table I. The control group included 43 healthy subjects from the same geographic region and socioeconomic background, age and ethnic background matched with the patients (with a mean age of $10.0 \pm 03.81$, range: $4-16$ years). They were attending the Out-patient Clinic of MRCE at NRC, Egypt for a routine health examination and periodic checkup. A health questionnaire, including questions such as name, age, sex, family history, and medications, was provided to each subject. The health state of all participants was determined by medical history and physical examination.

\section{Blood sampling}

Blood was withdrawn under complete aseptic conditions in accordance with the World Health Organization protocol for blood donation.

Serum levels of ficolin-2 were assayed using EIABab, ELISA kit (Cat No. E1907h) according to the manufacturer's instructions.

\section{Genotyping promoter region of FCN2}

Genomic DNA was extracted from whole blood using a commercial DNA extraction kit according to the manufacturer's protocol (Thermo Scientific Gene JET Whole Blood Genomic DNA Purification Mini Kit, \# K0781, \#K0782). The purified genomic DNA showed a 260/280 ratio between 1.7 to 1.9 . Rs 3124953 polymorphism (-602 promoter region) was determined by a predesigned TaqMan SNP genotyping assay (Applied Biosystems). Oligonucleotides used for the allelic discrimination assay for Rs3124953 were as follows: context sequences for Rs 3124953 ([VIC/FAM]) (Applied Biosystems ID: C_27461651_20) CTCTTCTCTCCTTTCCCTCCTGTTC [A/G] TGTGCCCCTGTGCTCTACATACTGC. The reaction was performed in a $25 \mu \mathrm{l}$ final volume with real time polymerase chain reaction using Quant Studio Real Time PCR System 12K Flex (Applied Biosystems). For genotyping a quality control, duplicate samples and negative controls were included to en-

Table I. Clinical, demographic and laboratory characteristics of patients with rheumatic fever only and rheumatic heart disease versus controls

\begin{tabular}{|c|c|c|c|c|}
\hline Parameter & RFo $(n=15)$ & $\operatorname{RHD}(n=62)$ & Controls $(n=43)$ & $P$-value \\
\hline Age [years] & $12(8.5-16)$ & $15(13-18)$ & $10(6-13)$ & $0.01^{a} / 0.05^{b}$ \\
\hline Gender (M/F) & $\begin{array}{c}10(66.67 \%) / \\
5(33.33 \%)\end{array}$ & $\begin{array}{l}30(48.4 \%) / \\
32(51.6 \%)\end{array}$ & $\begin{array}{l}19(44.2 \%) / \\
24(55.8 \%)\end{array}$ & $0.314^{a} / 0.456^{b}$ \\
\hline Duration [years] & $4.69 \pm 3.64$ & $6.15 \pm 4.43$ & - & 0.313 \\
\hline $\begin{array}{l}\text { Clinical characteristics } \\
(y / n)\end{array}$ & $3(20 \%)$ & $56(90.3 \%)$ & - & $<0.001$ \\
\hline Carditis & $12(80 \%)$ & $6(9.7 \%)$ & & \\
\hline Arthritis & $\begin{array}{c}15(100 \%) \\
0(0 \%)\end{array}$ & $\begin{array}{l}46(74.2 \%) \\
16(25.8 \%)\end{array}$ & - & 0.032 \\
\hline Subcutaneous nodules & $\begin{array}{c}0(0 \%) \\
15(100 \%) \\
\end{array}$ & $\begin{array}{c}2(3.2 \%) \\
60(96.8 \%)\end{array}$ & - & 1 \\
\hline Chorea & $\begin{array}{c}0(0 \%) \\
15(100 \%)\end{array}$ & $\begin{array}{c}6(9.7 \%) \\
56(90.3 \%)\end{array}$ & - & 0.336 \\
\hline Erythema marginatum & $\begin{array}{c}0(0 \%) \\
15(100 \%)\end{array}$ & $\begin{array}{c}0(0 \%) \\
62(100 \%)\end{array}$ & - & - \\
\hline $\mathrm{BMI}\left[\mathrm{kg} / \mathrm{cm}^{2}\right]$ & $19.10 \pm 5.31$ & $19.69 \pm 3.74$ & $20.60 \pm 1.44$ & $0.243^{a} / 0.237^{b}$ \\
\hline $\mathrm{SBP}[\mathrm{mm} \mathrm{Hg}]$ & $93.08 \pm 14.22$ & $103.33 \pm 14.74$ & $95.54 \pm 9.70$ & $0.012^{\mathrm{a}} / 0.002^{\mathrm{b}}$ \\
\hline $\mathrm{DBP}[\mathrm{mm} \mathrm{Hg}]$ & $65.00 \pm 6.77$ & $66.56 \pm 11.77$ & $61.55 \pm 10.10$ & $0.491^{\mathrm{a}} / 0.065^{\mathrm{b}}$ \\
\hline
\end{tabular}

Data presented as mean $\pm S D$, percentages or (range) where appropriate. Age of healthy control and patient groups was presented as median and interquartile range (25-75\%). RFo - rheumatic fever only, RHD - rheumatic heart disease, (y/n) - yes/no, SBP - systolic blood pressure, DBP - diastolic blood pressure, BMI - body mass index, ${ }^{a} p$ between RFo vs. RHD, ${ }^{b} p$ among different groups by ANOVA. $P<0.05$ was considered significant. 
sure accuracy. For the investigation of $-4 A>G$ polymorphism, a simple PCR-RFLP was employed. Each DNA sample (150 ng) was added to a reaction volume of $25 \mu \mathrm{l}$, containing $2.5 \mu \mathrm{l}$ of $10 \times$ polymerase buffer, $1 \mathrm{U}$ of Taq DNA polymerase (Ferments), $2 \mathrm{mM}$ of $\mathrm{MgCl}_{2}, 200 \mu \mathrm{M}$ of dNTP mix and $0.4 \mu \mathrm{M}$ of primers (Forward Primer 5'GAGCAGCCCTGGAGATGAT 3' and Reverse Primer 5'AGAAGTTTCCAGGAGGAGGC $3^{\prime}$ ). The reaction was performed using a VERITI Thermal Cycler (Applied Biosystems)under the following conditions: $95^{\circ} \mathrm{C}$ for $3 \mathrm{~min}$, then 35 cycles of $95^{\circ} \mathrm{C}$ for $30 \mathrm{~s}, 63 \mathrm{C}$ for $30 \mathrm{~s}$ and $72^{\circ} \mathrm{C}$ for $15 \mathrm{~S}$ followed by a final extension step of $72^{\circ} \mathrm{C}$ for $5 \mathrm{~min}$. After that, the PCR products $(10 \mu \mathrm{l})$ were treated with $1 \mathrm{U}$ of Mboll enzyme (Ferments) at $37^{\circ} \mathrm{C}$ for $30 \mathrm{~min}$. The digestion products were further analyzed using polyacrylamide gel $6 \%$.

\section{Statistical analysis}

Data were coded and entered using the statistical package SPSS version 23. Data were summarized using mean, standard deviation, median, minimum and maximum for quantitative variables and frequencies (number of cases) and relative frequencies (percentages) for categorical variables. Power analysis was used to calculate the minimum sample size required to accept the outcome of a statistical test with a particular level of confidence. A sample size of 20 will give us approximately $80 \%$ power ( $\alpha=0.05$, two-tail) to reject the null hypothesis of zero correlation. We used power calculations performed by the Power and Precision program (Biostat) to determine the number of chromosomes required to detect a significant difference between the polymorphism frequency in the reference population and the expected frequency. Power commonly sets at $80 \%$; however, at that level, a polymorphism would be missed $20 \%$ of the time. Comparisons between groups were done using the unpaired $t$-test when comparing 2 groups and analysis of variance (ANOVA) with multiple comparisons post hoc test when comparing more than 2 groups in normally distributed quantitative variables while the non-parametric Kruskal-Wallis test and Mann-Whitney test were used for non-normally distributed quantitative variables (Mann-Whitney test adjusted for multiple comparisons was used as a post hoc test). For comparing categorical data, the chi square $\left(\chi^{2}\right)$ test was performed. The exact test was used instead when the expected frequency was less than 5 . Correlations between quantitative variables were done using Pearson's correlation coefficient. Genotype and allele frequencies were compared between the disease and the control groups using the $\chi^{2}$ test. The odds ratio (OR) with $95 \%$ confidence intervals was calculated. Haplotypes were calculated by direct counting of alleles in each patient. Hardy-Weinberg equilibrium (HWE) was calculated as done previously [25]. The ROC curve was constructed with area under curve analysis performed to detect the best cutoff value of ficolin for detection of rheumatic heart and rheumatic fever. Linear regression analysis was done to predict ficolin using different factors. Logistic regression was done to detect independent predictors of rheumatic heart disease. $P$-values less than 0.05 were considered as statistically significant.

\section{Results}

Among patients, the most prevalent major criteria at diagnosis were carditis $(n=59 ; 75.6 \%)$ and arthritis ( $n=62 ; 79.5 \%)$; chorea was present in $6(7.7 \%)$ patients, whereas no patient presented erythema marginatum or subcutaneous nodules. The mean level of erythrocyte sedimentation rate (ESR) was $67 \pm 36.6 \mathrm{~mm} / \mathrm{h}$, total leucocytic count was $10.43 \pm 36.60$ and hemoglobin concentration (Hb) was $10.76 \pm 0.52 \mathrm{~g} / \mathrm{dl}$.

All patients were receiving secondary prophylaxis with 3-weekly injections of benzathine penicillin. In the subgroup of patients with RHD, the mitral valve was the most frequently affected ( $n=41 ; 66.13 \%)$, aortic valve in 1 (1.61\%) and mitral combined with aortic valve disease was seen in $20(32.26 \%)$ patients. Valvular involvement included mitral stenosis in $3(4.84 \%)$, mild mitral regurgitation in 37 (59.68\%) patients, moderate mitral regurgitation in $9(14.52 \%)$ patients, severe mitral regurgitation in $11(17.74 \%)$ patient, trivial mitral regurgitation in 2 (3.23\%), mild aortic regurgitation in 11 (17.74\%) subjects, moderate aortic regurgitation in 6 (9.68\%), severe aortic regurgitation in $3(4.84 \%)$ patients and trivial aortic regurgitation in 1 (1.61\%).

Clinical, demographical and laboratory characteristics of the patients with rheumatic fever only and rheumatic heart disease versus controls are shown in Table I.

Echocardiographic findings of the patients with rheumatic fever only and rheumatic heart disease are shown in Table II.

\section{Comparisons of ficolin-2 levels in the peripheral blood of the studied groups}

Serum ficolin-2 in the total RF group was statistically significantly lower than that in the controls $(53.33 \pm 9.96$ and $83.78 \pm 15.25 \mathrm{pg} / \mathrm{ml}$, respectively, $p<0.001$ ) (Figure $1 \mathrm{~A}$ ). Peripheral blood ficolin-2 levels in the RFo group were not significantly different from those in the RHD children (51.46 $\pm 10.21 \mathrm{pg} / \mathrm{ml}$ and $53.79 \pm 9.93 \mathrm{pg} / \mathrm{ml}$ respectively, $p=0.478$ ) (Figure $1 \mathrm{~B}$ ). Serum ficolin-2 in the RHD group was highly significantly lower than that in the controls $(53.79 \pm 9.93$ vs. $83.78 \pm 15.25 \mathrm{pg} / \mathrm{ml}$, respectively, $p<0.001$ ) (Figure $1 \mathrm{C}$ ). 
Table II. Echocardiographic findings of patients with rheumatic fever only and rheumatic heart disease

\begin{tabular}{|c|c|c|c|}
\hline Parameter & RFo $(n=15)$ & $\operatorname{RHD}(n=62)$ & $P$-value \\
\hline \multicolumn{4}{|c|}{ M-mode echocardiography findings: } \\
\hline $\mathrm{LA}[\mathrm{mm}]$ & $23.00 \pm 11.14$ & $25.71 \pm 13.61$ & 0.133 \\
\hline LVEDD $[\mathrm{mm}]$ & $32.82 \pm 15.39$ & $37.36 \pm 19.27$ & 0.041 \\
\hline LVESD $[\mathrm{mm}]$ & $20.98 \pm 10.08$ & $23.84 \pm 12.54$ & 0.063 \\
\hline $\mathrm{EF}(\%)$ & $68.19 \pm 7.25$ & $69.08 \pm 7.45$ & 0.602 \\
\hline FS (\%) & $36.81 \pm 5.05$ & $37.53 \pm 4.92$ & 0.447 \\
\hline \multicolumn{4}{|c|}{ Doppler echocardiography: } \\
\hline E wave $[\mathrm{cm} / \mathrm{s}]$ & $0.94 \pm 0.19$ & $1.05 \pm 0.29$ & 0.261 \\
\hline A wave $[\mathrm{cm} / \mathrm{s}]$ & $0.55 \pm 0.14$ & $0.58 \pm 0.22$ & 0.839 \\
\hline E/A ratio & $1.79 \pm 0.47$ & $1.89 \pm 0.51$ & 0.674 \\
\hline $\mathrm{DC}$ time $[\mathrm{s}]$ & $161.60 \pm 23.67$ & $181.42 \pm 51.72$ & 0.166 \\
\hline $\mathrm{MV}$ area $\left[\mathrm{mm}^{2}\right]$ & $5.81 \pm .92$ & $4.98 \pm 1.77$ & 0.6 \\
\hline
\end{tabular}

LA - left atrium, LVEDD - left ventricular end diastolic dimension, LVESD - left ventricular end systolic diameter, FS - fraction shortening, $E F$ - ejection fraction, E- early peak diastolic velocity, A - late peak diastolic velocity, DC - deceleration time, MV area - mitral valve area. $P<0.05$ was considered significant

A

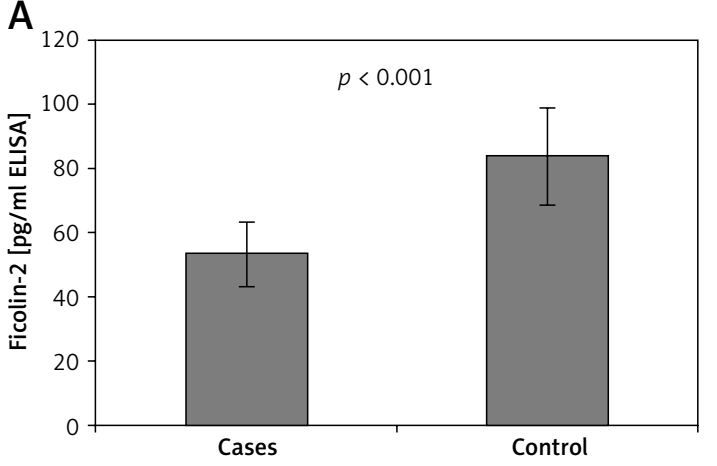

C

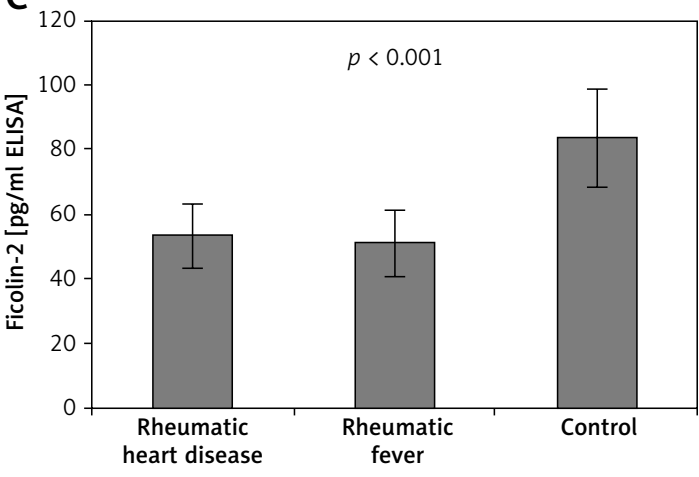

Distribution of FCN2 genotypes, alleles and haplotypes

FCN2 allele and genotype frequencies were in accordance with Hardy-Weinberg expectations for both groups $\left(\chi^{2}=0.04, p=0.836\right.$ for FCN2 -602 promoter region and $\chi^{2}=2.14, p=0.1436$ for FCN2 -4 promoter region). Genetic association analyses with Pearson's $\chi^{2}$ test was performed and data are summarized in Table III.
B

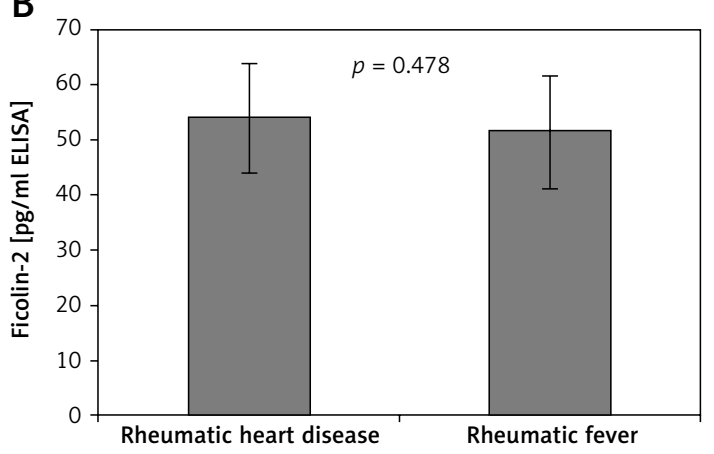

Figure 1. Comparison of serum levels of ficolin-2 in the studied groups (mean \pm SD). A - Serum ficolin-2 in the total RF group were highly significantly lower than those in the controls $(53.33 \pm 9.96 \mathrm{pg} / \mathrm{ml}$ and $83.78 \pm 15.25 \mathrm{pg} / \mathrm{ml}$, respectively, $p<0.001$ ). B - Peripheral blood ficolin-2 levels in the RFo group were not significantly different than those in the RHD patients $(51.46 \pm 10.21 \mathrm{pg} / \mathrm{ml}$ and $53.79 \pm 9.93$ $\mathrm{pg} / \mathrm{ml}$ respectively, $p=0.478)$. $C$ - Serum ficolin-2 in the RFo and RHD groups were highly significantly lower than those in the controls $(53.33 \pm 9.96 \mathrm{pg} /$ $\mathrm{ml}$ and $53.79 \pm 9.93 \mathrm{pg} / \mathrm{ml}$, vs. $83.78 \pm 15.25 \mathrm{pg} / \mathrm{ml}$, respectively, $p<0.001$ )

Analyzing the FCN2 gene, the genotype AA at the -4 position was observed more frequently in total RF patients, as compared to healthy subjects (28.6\% vs. $7 \%, p=0.005, \mathrm{OR}=5.333,95 \% \mathrm{Cl}$ : 1.493-19.052). Comparing the frequency of the A allele in total RF patients and control subjects, the A allele was significantly higher in total RF patients than in the control group ( $57.1 \%$ vs. $41.9 \%$ ) and was identified as a possible risk factor for the 
Table III. Ficolin-2 promoter genotypes and haplotypes at positions -602/-4 in all patients versus controls

\begin{tabular}{|c|c|c|c|c|c|c|c|c|}
\hline \multirow[t]{2}{*}{ Variable } & & \multicolumn{2}{|c|}{ Total RF $(n=77)$} & \multicolumn{2}{|c|}{ Controls $(n=43)$} & \multirow[t]{2}{*}{$P$-value } & \multirow[t]{2}{*}{ OR } & \multirow[t]{2}{*}{$95 \% \mathrm{Cl}$} \\
\hline & & Count & $\%$ & Count & $\%$ & & & \\
\hline \multirow[t]{5}{*}{-602 position } & AA & 1 & 1.3 & 1 & 2.3 & 1 & 0.553 & $0.034-9.063$ \\
\hline & $A G$ & 14 & 18.2 & 9 & 20.9 & 0.714 & 0.840 & $0.329-2.139$ \\
\hline & GG & 62 & 80.5 & 33 & 76.7 & 0.625 & 1.253 & $0.507-3.095$ \\
\hline & A allele & 16 & 10.4 & 11 & 12.8 & 0.572 & 0.791 & $0.349-1.790$ \\
\hline & $\mathrm{G}$ allele & 138 & 89.6 & 75 & 87.2 & & & \\
\hline \multirow[t]{5}{*}{-4 position } & AA & 22 & 28.6 & 3 & 7.0 & 0.005 & 5.333 & $1.493-19.052$ \\
\hline & $A G$ & 44 & 57.1 & 30 & 69.8 & 0.173 & 0.578 & $0.262-1.276$ \\
\hline & GG & 11 & 14.3 & 10 & 23.3 & 0.215 & 0.550 & $0.212-1.426$ \\
\hline & A allele & 88 & 57.1 & 36 & 41.9 & 0.023 & 1.852 & $1.085-3.159$ \\
\hline & $\mathrm{G}$ allele & 66 & 42.9 & 50 & 58.1 & & & \\
\hline \multirow{4}{*}{$\begin{array}{l}-602 /-4 \\
\text { haplotypes }\end{array}$} & $A / A$ & 14 & 9.1 & 7 & 8.1 & 0.469 & 1.437 & $0.538-3.842$ \\
\hline & $\mathrm{G} / \mathrm{A}$ & 74 & 48.1 & 29 & 33.7 & 0.038 & 1.834 & $1.034-3.252$ \\
\hline & $A / G$ & 2 & 1.3 & 4 & 4.7 & 0.249 & 0.359 & $0.063-2.046$ \\
\hline & $\mathrm{G} / \mathrm{G}$ & 64 & 41.6 & 46 & 53.5 & Reference & 1 & \\
\hline
\end{tabular}

Fisher's exact test was done. RF-rheumatic fever, $O R$ - odds ratio, $\mathrm{Cl}$ - confidence interval. $P<0.05$ was considered significant.

development of $\operatorname{RF}(p=0.023, \mathrm{OR}=1.852,95 \% \mathrm{Cl}$ : 1.085-3.159). Frequencies of AG and GG genotypes were 57.1 and $14.3 \%$ in the total RF patients and 69.8 and $23.3 \%$ respectively in the control group.

A statistically significant difference was not found when comparing FCN2 -602 promoter region genotypes in total RF patients and the controls. Frequencies of $\mathrm{AA}, \mathrm{AG}$ and $\mathrm{GG}$ genotypes were $1.3,18.2$ and $80.5 \%$ of the total RF, respectively, while those of the control group were 2.3,
20.9 and $76.8 \%$ in the same order $(p=0.714$ and 0.625 , respectively). The frequency of $G$ and A alleles in total RF patients was not significantly different than that in the control group $(89.6 \%$ vs. $87.2 \%$ and $10.4 \%$ vs. $12.8 \%$, respectively $p=0.572$ ).

When analyzing the FCN2 haplotypes, the only finding was that -602/-4 G/A was significantly more frequently represented in total RF when compared to the healthy subjects $(74,48.1 \%$ vs. $29,33.7 \%$, $\mathrm{OR}=1.834,95 \% \mathrm{Cl}: 1.034-3.252, p=0.038)$.

Table IV. Ficolin-2 promoter region at positions $-602 /-4$ in patients with rheumatic fever only, rheumatic heart disease versus controls

\begin{tabular}{|c|c|c|c|c|c|c|c|c|}
\hline \multirow[t]{2}{*}{ Variable } & & \multicolumn{2}{|c|}{ RFo $(n=15)$} & \multicolumn{2}{|c|}{ RHD $(n=62)$} & \multicolumn{2}{|c|}{ Controls $(n=43)$} & \multirow[t]{2}{*}{$P$-value } \\
\hline & & Count & $\%$ & Count & $\%$ & Count & $\%$ & \\
\hline \multirow[t]{5}{*}{-602 position } & AA & 1 & 6.7 & 0 & 0 & 1 & 2.3 & 0.416 \\
\hline & $A G$ & 2 & 13.3 & 12 & 19.4 & 9 & 20.9 & \\
\hline & GG & 12 & 80.0 & 50 & 80.6 & 33 & 76.7 & \\
\hline & Allele A & 4 & 13.3 & 12 & 9.7 & 11 & 12.8 & 0.651 \\
\hline & Allele G & 26 & 86.7 & 112 & 90.3 & 75 & 87.2 & \\
\hline \multirow[t]{5}{*}{-4 position } & $\mathrm{AA}$ & 4 & 26.7 & 18 & 29.0 & 3 & 7.0 & 0.013 \\
\hline & $A G$ & 11 & 73.3 & 33 & 53.2 & 30 & 69.8 & \\
\hline & GG & 0 & 0 & 11 & 17.7 & 10 & 23.3 & \\
\hline & Allele A & 19 & 63.3 & 69 & 55.6 & 36 & 41.9 & 0.055 \\
\hline & Allele $\mathrm{G}$ & 11 & 36.7 & 55 & 44.4 & 50 & 58.1 & \\
\hline
\end{tabular}

Fisher's exact test was done, RFo - rheumatic fever only, RHD - rheumatic heart disease. $P<0.05$ was considered significant. 
The frequency of the A/A homozygotes of the FCN2 - 4 promoter region was significantly higher in $\mathrm{RHD}$ patients than in the controls $(26.7 \% / 29.0 \%$ vs. $7.0 \%, p=0.013)$. Also the A allele was insignificantly higher in RHD than that of controls (63.3\%/55.6\% vs. $41.9 \%, p=0.055)$ (Table IV).

In addition, by using logistic regression, FCN2 AA genotypes at the -4 position together with G/A haplotypes of -602 and -4 position were analyzed as risk factors for the development of RF. After adjusting for confounding factors (age and gender), an OR of 8.646 (95\% Cl: 0.994-75.232, $p=0.051)$ was observed for FCN2 AA genotypes at the -4 position.

\section{Relationship between ficolin-2 level and FCN2 promoter region at position -602/-4 in total RF patients}

There was no significant difference in the distribution of ficolin- 2 concentration among the different genotypes and alleles of FCN2 at -602 and -4 positions in total RF patients $(p=0.250$ and $p=0.304$ ), while the haplotype $-602 /-4 \mathrm{G} / \mathrm{A}$ was insignificantly related to low median levels of ficolin-2 ( $p=0.085$ ) (Table V). Also, no significant difference was found in the distribution of ficolin- 2 concentration among the different genotypes and alleles of FCN2 at -602 and -4 positions in $\operatorname{RHD}(p=0.665$ and $p=0.357$ respectively) and in controls ( $p=0.702$ and $p=0.185)$, but it was insignificantly different in RFo $(p=0.088$ and $p=0.802$ ) (data not shown).

However, when pooling AG + GG genotypes of FCN2 at the -4 position vs. AA diplotype, we found that the ficolin-2 level was significantly lower with AA genotypes than GG + AG genotypes (56.68 \pm 17.90 vs. $66.05 \pm 18.79, p=0.008$ ) (Table VI). Also when combining the presence of GG genotypes of FCN 2 at the -602 position with AA genotypes at the -4 position in total RF patients, the serum ficolin-2 level was insignificantly lower than that in their absence $(58.43 \pm 19.86 \mathrm{pg} / \mathrm{ml}$ vs. 65.15 $\pm 18.65, p=0.066$ ) (Table VII).

There were no significant differences between different genotypes of FCN2 -602 and -4 A > G positions as regards the occurrence of arthritis, carditis, chorea, erythema marginatum and subcutaneous nodules.

\section{Correlations between serum ficolin-2 levels and different cardiac parameters}

A positive correlation was found between serum ficolin-2 levels and systolic cardiac function as presented by left ventricular ejection fraction (LVEF) \% ( $r=0.258, p=0.023)$. Negative correlations were found between serum ficolin-2 levels and LVEDD $(r=-0.303, p=0.007)$, LVESD $(r=-0.343, p=0.002)$, left atrium (LA) dimension $(r=-0.274, p=0.016)$ and $\operatorname{ESR}(r=-0.437, p=$ 0.042 ) (Figure 2). Also when pooling the presence of GG of the -602 position and AA of the -4 position simultaneously with their absence, we found a significant difference in $E$ wave $(0.93 \pm 0.24,1.06$ $\pm 0.28, p=0.029$ ) (Table VII).

A positive correlation was found between $\mathrm{HB}$ concentration and serum ficolin-2 levels $(r=0.799$, $p=0.017)$. A negative correlation was found between serum ficolin-2 levels and TLC $(r=0.817$, $p=0.047)$.

For comparison of the gross achievement of the biomarkers, distinctly of the pre-specified threshold levels, we tested the comprehensive degree

Table V. Relationship between ficolin level and FCN2 promoter region at position -602/-4 in total RF children

\begin{tabular}{|c|c|c|c|c|c|c|c|}
\hline \multirow[t]{2}{*}{ Variable } & & \multicolumn{5}{|c|}{ Ficolin-2 levels [pg/ml] } & \multirow[t]{2}{*}{$P$-value } \\
\hline & & Mean & $\begin{array}{l}\text { Standard } \\
\text { deviation }\end{array}$ & Median & Minimum & Maximum & \\
\hline \multirow[t]{5}{*}{-602 position } & AA & 36.90 & 0 & 36.90 & 36.90 & 36.90 & \multirow[t]{3}{*}{0.250} \\
\hline & AG & 53.06 & 12.27 & 53.65 & 31.80 & 75.50 & \\
\hline & GG & 53.66 & 9.33 & 55.15 & 35.20 & 77.20 & \\
\hline & A allele & 51.04 & 12.69 & 48.65 & 31.80 & 75.50 & \multirow[t]{2}{*}{0.331} \\
\hline & G allele & 53.60 & 9.58 & 55.15 & 31.80 & 77.20 & \\
\hline \multirow[t]{5}{*}{-4 position } & AA & 51.30 & 7.87 & 49.45 & 40.20 & 65.40 & \multirow[t]{3}{*}{0.304} \\
\hline & $A G$ & 53.43 & 10.63 & 55.30 & 31.80 & 75.50 & \\
\hline & $\mathrm{GG}$ & 57.00 & 10.71 & 58.70 & 36.90 & 77.20 & \\
\hline & $A$ & 52.37 & 9.32 & 51.15 & 31.80 & 75.50 & 0.164 \\
\hline & G allele & 54.62 & 10.62 & 57.00 & 31.80 & 77.20 & \\
\hline \multirow{4}{*}{$\begin{array}{l}-602 /-4 \\
\text { haplotypes }\end{array}$} & $\mathrm{A} / \mathrm{A}$ & 61.05 & 18.35 & 62.00 & 31.80 & 100.10 & \multirow[t]{4}{*}{0.085} \\
\hline & $\mathrm{G} / \mathrm{A}$ & 61.58 & 18.68 & 57.00 & 35.20 & 120.50 & \\
\hline & $\mathrm{A} / \mathrm{G}$ & 69.30 & 19.67 & 73.25 & 36.90 & 91.70 & \\
\hline & $\mathrm{G} / \mathrm{G}$ & 66.76 & 18.96 & 63.35 & 31.80 & 114.10 & \\
\hline
\end{tabular}


Table VI. Clinical, laboratory and echocardiographic characteristics of total RF patients with different FCN2 genotypes at position $-602 /-4$

\begin{tabular}{|lcccccc|}
\hline Parameter & \multicolumn{3}{c}{-4 position } & \multicolumn{3}{c|}{-602 position } \\
\cline { 2 - 7 } & $\begin{array}{c}\text { AG }+\mathrm{GG} \\
(n=55)\end{array}$ & $\begin{array}{c}\text { AA } \\
(n=22)\end{array}$ & $P$-value & $\begin{array}{c}\text { AA }+ \text { AG } \\
(n=15)\end{array}$ & $\begin{array}{c}\text { GG } \\
(n=62)\end{array}$ & $P$-value \\
\hline Age [years] & $13.41 \pm 4.92$ & $14.17 \pm 4.75$ & 0.427 & $13.40 \pm 4.27$ & $13.64 \pm 5.04$ & 0.848 \\
\hline Duration [years] & $5.44 \pm 4.43$ & $6.80 \pm 3.90$ & 0.109 & $5.77 \pm 4.11$ & $5.88 \pm 4.38$ & 0.987 \\
\hline Ficolin-2 [pg/ml] & $66.05 \pm 18.79$ & $56.68 \pm 17.90$ & 0.008 & $63.26 \pm 18.29$ & $64.30 \pm 19.18$ & 0.974 \\
\hline BMI [kg/m²] & $19.48 \pm 4.08$ & $19.42 \pm 4.04$ & 0.826 & $19.27 \pm 4.30$ & $19.50 \pm 4.02$ & 0.837 \\
\hline LA [mm] & $25.14 \pm 13.99$ & $26.21 \pm 10.07$ & 0.264 & $21.13 \pm 12.53$ & $26.51 \pm 12.90$ & 0.052 \\
\hline LVEDD [mm] & $35.35 \pm 19.76$ & $40.59 \pm 13.63$ & 0.643 & $33.48 \pm 18.98$ & $37.66 \pm 18.18$ & 0.695 \\
\hline LVESD [mm] & $22.25 \pm 12.48$ & $26.66 \pm 9.92$ & 0.396 & $22.55 \pm 11.43$ & $23.75 \pm 12.08$ & 0.799 \\
\hline EF (\%) & $69.00 \pm 7.05$ & $67.86 \pm 7.52$ & 0.393 & $67.81 \pm 5.58$ & $68.89 \pm 7.51$ & 0.787 \\
\hline FS (\%) & $37.36 \pm 4.63$ & $36.95 \pm 5.32$ & 0.447 & $36.13 \pm 4.26$ & $37.51 \pm 4.92$ & 0.404 \\
\hline E wave [cm/s] & $1.04 \pm 0.28$ & $1.00 \pm 0.26$ & 0.333 & $1.05 \pm 0.35$ & $1.02 \pm 0.25$ & 0.652 \\
\hline A wave [cm/s] & $0.57 \pm 0.24$ & $0.56 \pm 0.13$ & 0.661 & $0.53 \pm 0.15$ & $0.58 \pm 0.22$ & 0.618 \\
\hline E/A ratio & $1.91 \pm 0.55$ & $1.80 \pm 0.37$ & 0.467 & $2.04 \pm 0.59$ & $1.83 \pm 0.48$ & 0.188 \\
\hline DC time [s] & $177.01 \pm 50.98$ & $179.32 \pm 40.23$ & 0.601 & $175.69 \pm 33.51$ & $178.23 \pm 50.99$ & 0.702 \\
\hline MV area [mm²] & $5.00 \pm 1.71$ & $5.50 \pm 2.12$ & 0.765 & $4.90 \pm 1.32$ & $5.13 \pm 1.87$ & 0.612 \\
\hline
\end{tabular}

Data presented as mean $\pm S D$, percentages or (range) where appropriate. BMI-body mass index, LA - left atrium, LVEDD - left ventricular end diastolic dimension, LVESD - left ventricular end systolic diameter, FS - fraction shortening, EF - ejection fraction, E - early peak diastolic velocity, A - late peak diastolic velocity, DC - deceleration time, MV area-mitral valve area. $P<0.05$ was considered significant.

Table VII. Clinical, laboratory and echocardiographic characteristics of total RF patients in the presence of GG of -602 and AA of -4 simultaneously

\begin{tabular}{|c|c|c|c|}
\hline \multirow[t]{2}{*}{ Parameter } & \multicolumn{3}{|c|}{ Presence of GG of -602 and AA of -4 simultaneously } \\
\hline & Yes $(n=16)$ & No $(n=61)$ & $P$-value \\
\hline Age [years] & $14.12 \pm 4.73$ & $13.48 \pm 4.92$ & 0.549 \\
\hline Duration [years] & $6.36 \pm 3.82$ & $5.73 \pm 4.44$ & 0.398 \\
\hline Ficolin-2 [pg/ml] & $58.43 \pm 19.86$ & $65.15 \pm 18.65$ & 0.066 \\
\hline $\mathrm{BMI}\left[\mathrm{kg} / \mathrm{m}^{2}\right]$ & $19.77 \pm 3.87$ & $19.37 \pm 4.12$ & 0.828 \\
\hline $\mathrm{LA}[\mathrm{mm}]$ & $26.28 \pm 11.77$ & $25.23 \pm 13.30$ & 0.566 \\
\hline LVEDD [mm] & $40.19 \pm 15.69$ & $35.97 \pm 18.93$ & 0.602 \\
\hline LVESD [mm] & $26.69 \pm 11.38$ & $22.68 \pm 11.99$ & 0.372 \\
\hline EF (\%) & $68.00 \pm 8.37$ & $68.86 \pm 6.87$ & 0.417 \\
\hline FS (\%) & $36.94 \pm 5.80$ & $37.32 \pm 4.56$ & 0.426 \\
\hline E wave $[\mathrm{cm} / \mathrm{s}]$ & $0.93 \pm 0.24$ & $1.06 \pm 0.28$ & 0.029 \\
\hline A wave $[\mathrm{cm} / \mathrm{s}]$ & $0.54 \pm 0.12$ & $0.58 \pm 0.23$ & 0.79 \\
\hline E/A ratio & $1.73 \pm 0.35$ & $1.92 \pm 0.54$ & 0.182 \\
\hline $\mathrm{DC}$ time $[\mathrm{s}]$ & $174.94 \pm 41.76$ & $178.49 \pm 49.59$ & 0.873 \\
\hline $\mathrm{MV}$ area $\left[\mathrm{mm}^{2}\right]$ & $6.44 \pm 1.90$ & $4.92 \pm 1.69$ & 0.316 \\
\hline
\end{tabular}

Data presented as mean $\pm S D$, percentages or (range) where appropriate. BMI - body mass index, LA - left atrium, LVEDD - left ventricular end diastolic dimension, LVESD - left ventricular end systolic diameter, FS - fraction shortening, EF - ejection fraction, $E$ - early peak diastolic velocity, $A$ - late peak diastolic velocity, $D C$ - deceleration time, MV area - mitral valve area. $P<0.05$ was considered significant. 
A

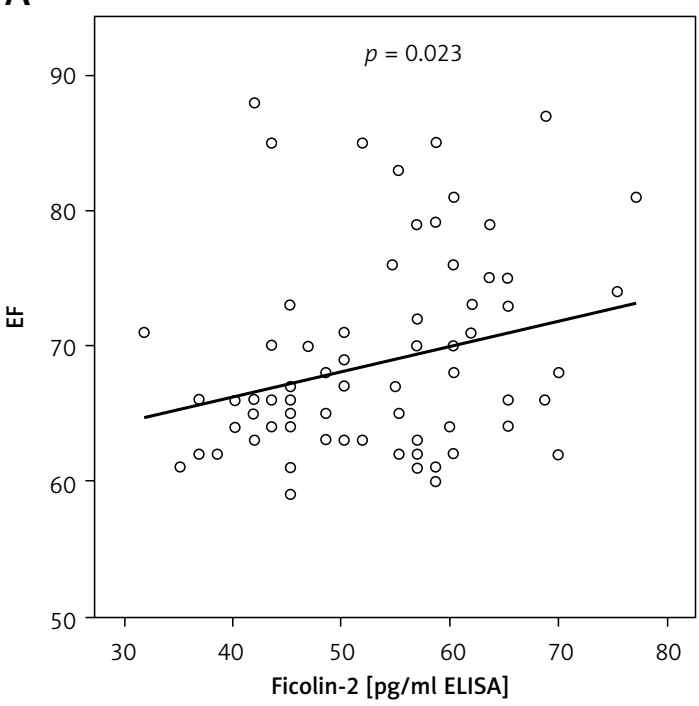

C

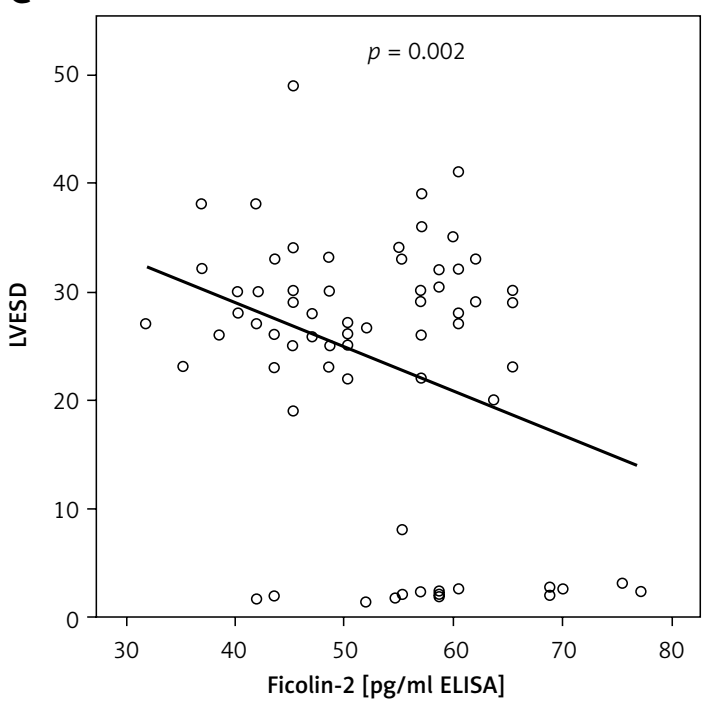

E

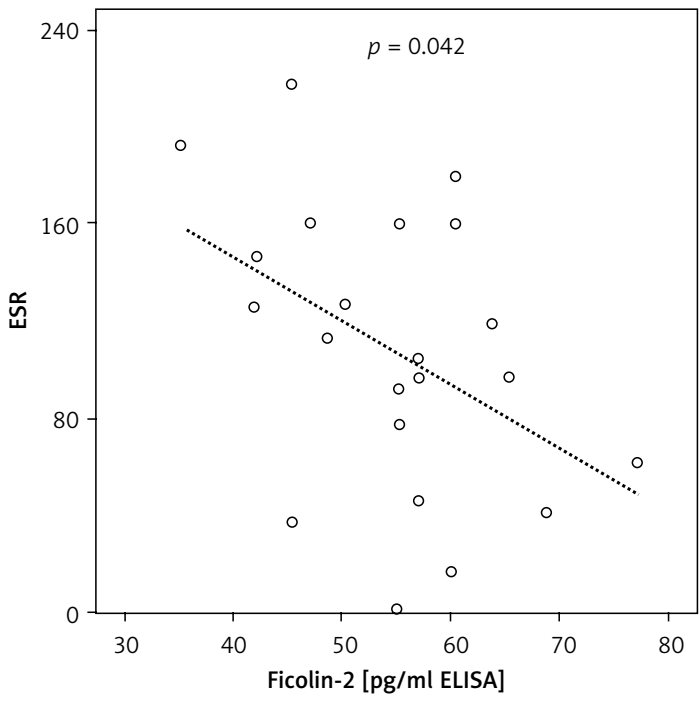

B

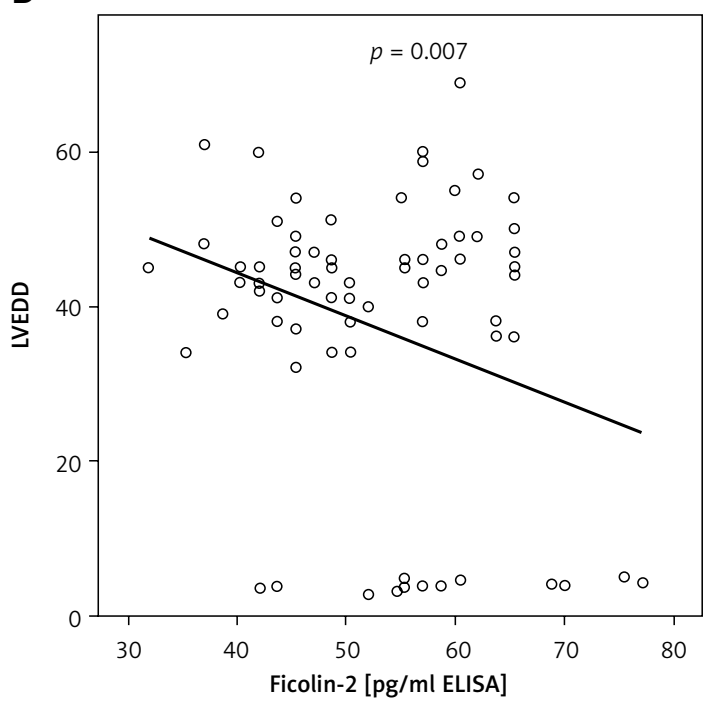

D

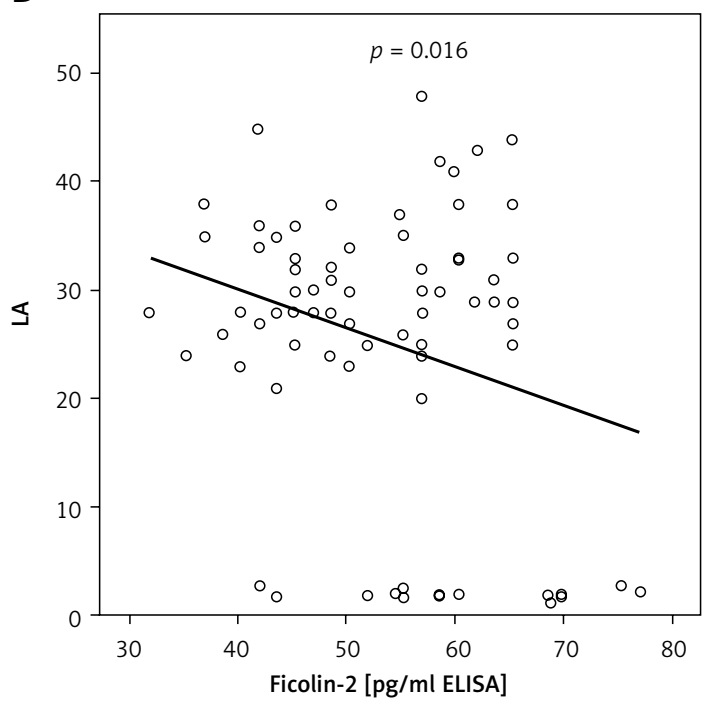

Figure 2. Pearson correlation between serum ficolin-2 levels and different cardiac parameters. A positive correlation with $\mathrm{EF} \%(r=0.258, p=0.023)(\mathbf{A})$ and negative correlation with LVEDD $(r=-0.303$, $p=0.007)(\mathrm{B}), \operatorname{LVESD}(r=-0.343, p=0.002)(\mathrm{C})$, LA $(r=-0.274, p=0.016)(D)$ and $\operatorname{ESR}(r=-0.437$, $p=0.042)(\mathrm{E})$ 
A

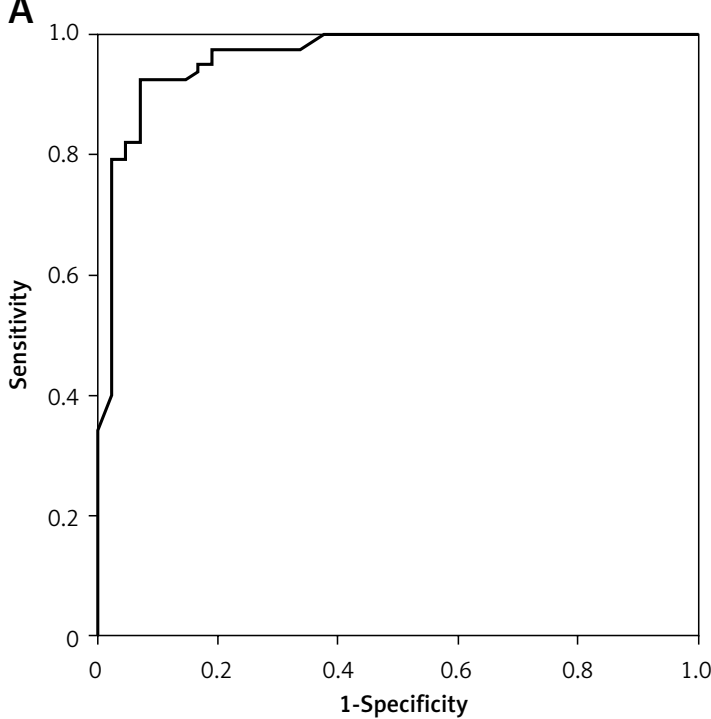

C

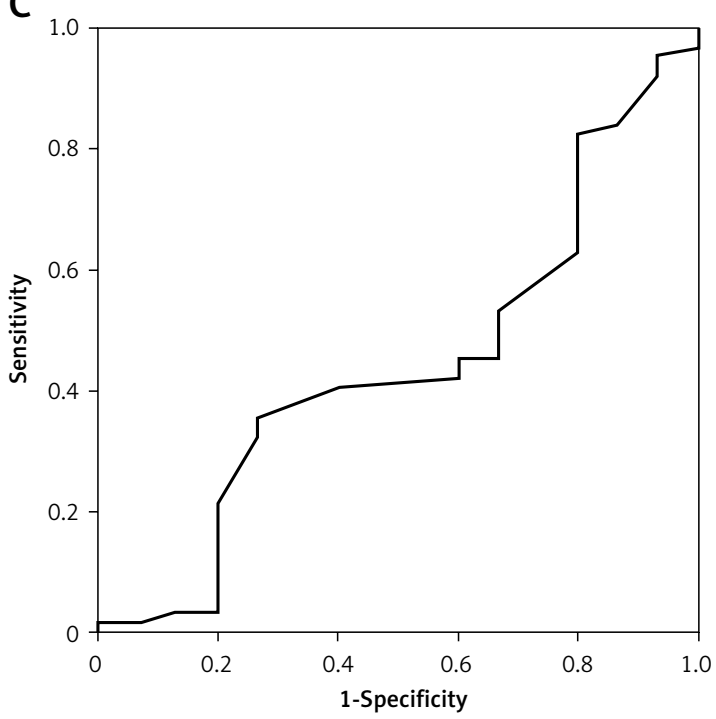

B

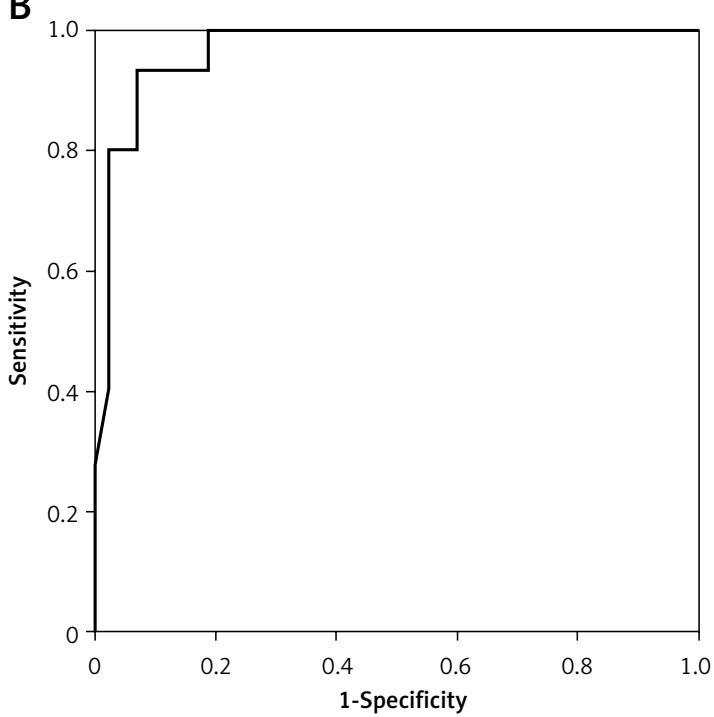

Figure 3. ROC curve analysis of ficolin-2 levels in total cases of RF children vs. controls. A - Assessment of ficolin-2 levels in total RF children vs. controls by ROC curve. AUC $1 / 4=0.963, p^{1 / 4}<0.001$. B - Assessment of serum ficolin-2 levels in only RF children vs. controls by ROC curve. AUC $1 / 4=0.967, p^{1 / 4}<$ 0.001 . C - Assessment of serum ficolin-2 levels in RF children vs. RHD children by ROC curve. AUC $1 / 4=$ $0.441, p^{1 / 4}=0.479$

Table VIII. Values of area under the curve for ficolin-2 levels in different studied groups

\begin{tabular}{|c|c|c|c|c|c|c|c|}
\hline \multirow{2}{*}{$\begin{array}{l}\text { Serum ficolin } \\
2 \text { levels }\end{array}$} & \multirow{2}{*}{$\begin{array}{c}\text { Area under } \\
\text { curve }\end{array}$} & \multirow[t]{2}{*}{$P$-value } & \multicolumn{2}{|c|}{$95 \%$ Confidence interval } & \multirow{2}{*}{$\begin{array}{l}\text { Cutoff } \\
\text { value }\end{array}$} & \multirow{2}{*}{$\begin{array}{c}\text { Sensitivity } \\
(\%)\end{array}$} & \multirow{2}{*}{$\begin{array}{c}\text { Specificity } \\
(\%)\end{array}$} \\
\hline & & & $\begin{array}{l}\text { Lower } \\
\text { bound }\end{array}$ & $\begin{array}{l}\text { Upper } \\
\text { bound }\end{array}$ & & & \\
\hline $\begin{array}{l}\text { Total RF vs. } \\
\text { controls }\end{array}$ & 0.963 & $<0.001$ & 0.928 & 0.998 & 66.2 & 92.2 & 92.9 \\
\hline $\begin{array}{l}\text { RF only vs. } \\
\text { controls }\end{array}$ & 0.967 & $<0.001$ & 0.925 & 1 & 70.2 & 100 & 81 \\
\hline RF only vs. RHD & 0.441 & 0.479 & 0.278 & 0.604 & - & - & - \\
\hline
\end{tabular}

No cutoff value as there is no difference between RHD and RF as regards ficolin-2 levels.

of test performance using the AUROC. As shown in Figure $3 \mathrm{~A}$, the AUC of serum ficolin-2 levels of total RF patients vs. controls was 0.963 , and the critical serum level of ficolin-2 associated with the risk of RF with RHD (cutoff value) was $66.2 \mathrm{pg} / \mathrm{ml}$, with sensitivity of $92.2 \%$ and specificity of $92.9 \%$ (95\% Cl: 0.928-0.998; $p^{1 / 4}<$ < 0.001). In RFo vs. con- trols the AUC of serum ficolin-2 levels was 0.967 and the critical serum level of ficolin-2 associated with the risk of RF without RHD was $70.2 \mathrm{pg} / \mathrm{ml}$, with sensitivity of $100 \%$ and specificity of $81 \%$ $\left(95 \%\right.$ Cl: $\left.0.925-1 ; p^{1 / 4}<0.001\right)$. There was no cutoff value as there was no difference between RHD and RFo in ficolin-2 levels (Table VIII). 


\section{Discussion}

The main assumption underlying the development of rheumatic fever is an autoimmune reaction resulting from molecular similarity between streptococcal antigens and cardiac, articular and central nervous system proteins [26]. Various genetic polymorphisms encoding for molecules participating in the immune responses have been suggested to contribute to RF and RHD susceptibility [27]. The activation cascade of complement proteins is the first line defense mechanism against infections by Streptococcus pyogenes. Because of its significant role in getting rid of rheumatic etiological agents, components of the lectin pathway deficiencies are held accountable for the susceptibility and the severity of rheumatic morbidities [28]. The existing literature about the involvement of ficolins and $\mathrm{MBL}$ in the pathogenesis of RF and RHD is still scarce; however, their dual role has been hypothesized [29].

To the best of our knowledge, this is the first study in our country of Caucasian origin to investigate two polymorphisms of the ficolin-2 gene together with its related genotypes and haplotypes and ficolin-2 levels in patients with RF and RHD.

Ficolin-2 levels were lower in our total RF, RF and RHD patients than in controls. However, peripheral blood ficolin-2 levels in the RF group were not significantly different from those in the RHD children. In addition, ROC curve analysis showed that ficolin-2 levels $<66.2 \mathrm{pg} / \mathrm{ml}$ increased the risk of RF/RHD while ficolin-2 levels $<70.2 \mathrm{pg} / \mathrm{ml}$ increased the risk of RF. As repeated S. pyogenes infections are needed for the development of RHD, impaired clearance of the pathogen may be due to reduced serum levels of ficolin-2, thus increasing the risk of an individual developing the chronic form of RF. Higher MBL and lower ficolin-2 levels are consistent with MASP-2 consumption due to intense MBL-driven complement activation. Previously, recurrent respiratory infections in children has been linked to low ficolin-2 serum levels [30]. Several studies have documented lower ficolin-2 levels in patients with myocardial infarction compared to control subjects, suggesting involvement of the protein in the activation process of complement following ischemia and necrosis of myocardium [31]. On the other hand, higher MASP-2 levels were associated with improved survival in patients with hematologic malignancies, specifically lymphoma [32]. Therefore, a distinct role in the pathogenesis of RF/CRHD can be attributed to the proteins of the lectin pathway, MBL, MASP-2 and ficolin-2. Whereas low levels of ficolin-2 due to a mutation at the transcriptional level might render an individual more vulnerable to recurrent and/or severe streptococcal infection, high levels of MBL with subsequent activation of the comple- ment may drive the inflammatory process, which leads to injury of myocytes in RF/CRHD patients.

The most interesting finding of our study was the FCN2 AA genotype of the -4 position, offering a hit for RF and RHD. This result suggests that this particular genotype may be a key player in the progression of the chronic form of RF. Patients carrying the FCN2 A polymorphism at -4 may be at major risk of recurrences having a higher probability to evolve in RHD. As a consequence, these patients should be carefully monitored and clinicians should consider the risks of secondary prophylaxis interruption [33]. Indeed, adherence to secondary prophylaxis for RF is usually poor, particularly in adolescents, and this is regarded as the main cause of RF recurrences and of RHD development [33, 34]. By focusing on the FCN haplotypes, a significantly higher haplotype frequency of -602/-4 G/A was observed in total RF compared to the controls. This result suggests that this particular haplotype may be a milestone in the development of RF.

A significantly higher frequency of AA genotypes of FCN2 at the -4 position together with a lower production of ficolin-2 levels was observed in patients with a history of rheumatic fever as a whole when pooling $A G+G G$ genotypes vs. AA genotypes at the -4 position. Also when combining the presence of GG genotypes of the -602 position with AA genotypes of the -4 position in total RF patients, the serum ficolin-2 level was insignificantly lower than that in their absence. Also, -602/-4 G/A haplotype is insignificantly related to low median levels of ficolin2. These data suggest that development of the cardiac manifestations of RF is linked to low levels of ficolin-2 and its associated genotypes, and that this association is due to a mechanism linked to FCN2 gene polymorphism and not to an acute-phase reaction. In our study, we did not find any protective genotype or haplotype for RF/RHD.

Many studies have revealed significantly different distribution of MBL2 and FCN2 alleles, genotypes and haplotypes among populations from different continents. These different genetic patterns may likely contribute to altered serum ficolin-2 and MBL levels, thus modulating disease susceptibility among world populations [35, 36].

In our present study, a positive correlation was found between serum ficolin-2 levels and systolic cardiac function as presented by EF \%. Negative correlations were found between serum FCN2 levels and LVEDD, LVESD, LA dimension and ESR. Also when comparing the presence of GG of the -602 position and AA of the -4 position simultaneously with their absence, we found a significant difference in E wave. In various diseases the activation of the complement proteins is an important inflammatory component. The molecular mechanisms behind the progressive loss of viable 
heart tissue in congestive heart failure (CHF) are only partly resolved. The lectin pathway initiator molecules MBL, ficolin-2 and ficolin-3 have all been shown to serve as bridging molecules between apoptotic bodies and phagocytic cells [37]. In cases of failing heart, multiple mechanisms contribute to death of myocytes, including necrosis, apoptosis, oncosis and autophagy; these processes are linked to complement activation [37]. Oliveira et al. confirmed a link between complement activation and myocardial failure, showing that increased deposition of terminal complement complex in failing myocardium was normalized after prolonged mechanical circulatory support [38].

Shahini et al. [39] reported that for HF patients with decreased properdin levels a main regulator of complement AP, increased levels of Nt-proBNP, a myocardial wall stress marker, and C-reactive protein (CRP), a marker of an inflammatory response, were detected, together with a decreased LVEF. Also, they observed that decreased properdin levels were associated with impaired systolic function (i.e., LVEF and cardiac output). In addition, when diastolic function was graded, they observed decreased levels of properdin in HF patients with the most restrictive filling dynamics. The cause of this connection is unknown, but because the diastolic dysfunction is related to systemic inflammation, often linked with inflammatory co-morbidities, the connection of AP activation to diastolic dysfunction could mirror the inflammation as a prevalent feature [40]. Furthermore, promoted myocardial fibrosis is another feature of diastolic dysfunction and promoted complement activation including also lectin pathway activation has been proposed to have a pathophysiological role in cardiac fibrosis induced by hyperglycemia, and systolic and diastolic dysfunction in an experimental model of acute hyperglycemia [41]. It is tempting to suppose that the mutual role of the AP in both inflammation and fibrogenesis may be of special importance for the occurrence of diastolic dysfunction.

Schoos et al. [31] postulated that myocardial cell death and altered self-structures in the failing human heart may bind ficolin-2, leading to ficolin plasma levels' reduction together with induction of complement activation. Baseline ficolin-2 plasma values above the median were significantly associated with larger LV volumes as indexed ESV and indexed EDV. Ficolin-2 is significantly associated with left ventricular dilatation (ESV and EDV) after ST segment elevation myocardial infarction (STEMI). This indicates that overall activation of the lectin pathway is associated with LV dilatation after STEMI. Yet, the lack of a consistent association of LV volume and function variation over time $(\triangle \mathrm{ESV}, \Delta \mathrm{EDV}, \Delta \mathrm{LVEF})$ renders it also likely that $\mathrm{LP}$ activation is associated with left ventricular dilatation per se, independent of the index STEMI event, meaning that a higher disease burden in the heart prior to the STEMI event (entailing a higher need of tissue homeostasis) involves LP activation, either causally or consequently. Therefore, other heart diseases such as chronic heart failure and dilated cardiomyopathy might constitute alternative study populations for LP molecules.

Prohászka et al. [37] supported this idea. First, cases with severe heart failure showed a decrease in ficolin-3 levels, and these low levels of ficolin-3 are a consequence of consumption after binding to altered self-structures in the myocardial cell wall, with subsequent complement activation, leading to inflammation and tissue damage. $\mathrm{Xu}$ et al. [42] reported that the minor allele of the apolipoprotein A1 -75G/A polymorphism is a protective factor for coronary artery disease, especially in the studies consistent with HWE.

The detection of genetic susceptibility loci through whole-genome scanning might supply a clinically beneficial genetic risk-prediction marker that will possibly permit an echocardiographic screening and the secondary prophylaxis to point to those at higher risk, thus decreasing the disease burden on the health system of this resource-strained continent [43]. When a hypothetical 2000 birth cohort analysis was done from a societal perspective, the prevention strategy in the form of genetic screening and prophylaxis for high-risk individuals decreased the number of RF patients and elevated the life span at an estimated discounted cost of $\$ 7900$ per quality-adjusted life-years gained. Genetic screening became the favorable (least expensive) strategy if the test specificity was $\geq 98 \%$, the annual cost of prophylaxis was $<\$ 550$, or the annual cost of caring for a patient with severe RHD increased to $\$ 32,000$. When utilized with available antibiotic prophylaxis, genetic testing has the possibility to supply a cost-effective strategy for the primary prevention of RF and its sequelae [44].

In conclusion, these data suggest that FCN2 AA genotypes at the -4 position together with G/A haplotypes of the -602 and -4 positions are linked to risk development of RF and progression to the chronic form. FCN-2 gene polymorphisms and protein levels are emerging as important players in the scope of RF development and establishment of RHD. The LP initiator molecule ficolin-2 is associated with LV dilatation. The clinical implications may be the identification of RF patients who can be damaged by a voluntary interruption of the antibiotic prophylaxis and, at the same time, to select those patients who may shorten the antibiotic prophylaxis with no consequences. In order to elucidate the role of MBL2 polymorphisms and to investigate the FCN2 poly- 
morphisms and their clinical implications together with systolic and diastolic cardiac functions in RF patients, future studies including larger populations are required.

\section{Acknowledgments}

Our work was supported by the National Research Centre in Egypt.

\section{Conflict of interest}

The authors declare no conflict of interest.

\section{References}

1. Chang C. Cutting edge issues in rheumatic fever. Clin Rev Allergy Immunol 2012; 42: 213-37.

2. Burke RJ, Chang C. Diagnostic criteria of acute rheumatic fever. Autoimmun Rev 2014; 13: 503-7.

3. Guilherme L, Kohler K, Kalil J. Rheumatic heart disease: mediation by complex immune events. Adv Clin Chem 2011; 53: 31-50.

4. Carapetis JR, McDonald M, Wilson NJ. Acute rheumatic fever. Lancet 2005; 366: 155-68.

5. GBD 2013 Mortality and Causes of Death Collaborators. Global, regional, and national age-sex specific all-cause and cause-specific mortality for 240 causes of death, 1990-2013: a systematic analysis for the Global Burden of Disease Study 2013. Lancet 2015; 385: 117-71.

6. Carapetis JR, Steer AC, Mulholland EK, Weber M. The global burden of group A streptococcal diseases. Lancet Infect Dis 2005; 5: 685-94.

7. Kumar RK, Tandon R. Rheumatic fever and rheumatic heart disease: the last 50 years. Indian J Med Res 2013; 137: 643-58.

8. Guilherme L, Fae K, Oshiro SE, Kalil J. Molecular pathogenesis of rheumatic fever and rheumatic heart disease. Exp Rev Mol Med 2005; 7: 1-15.

9. Mayilyan KR. Complement genetics, deficiencies, and disease associations. Protein Cell 2012; 3: 487-96.

10. Stager S, Alexander J, Kirby AC, et al. Natural antibodies and complement are endogenous adjuvants for vaccine-induced CD8+ T-cell responses. Nat Med 2003; 9: 1287-92.

11. Degn SE, Jensenius JC, Thiel S. Disease-causing mutations in genes of the complement system. Am J Hum Genet 2011; 88: 689-705.

12. Matsushita M, Endo Y, Fujita T. Structural and functional overview of the lectin complement pathway: its molecular basis and physiological implication. Arch Immunol Ther Exp (Warsz) 2013; 61: 273-83.

13. Runza VL, Schwaeble W, Mannel DN. Ficolins: novel pattern recognition molecules of the innate immune response. Immunobiology 2008; 213: 297-306.

14. Messias-Reason IJ, Schafranski MD, Kremsner PG, Kun JF. Ficolin 2 (FCN2) functional polymorphisms and the risk of rheumatic fever and rheumatic heart disease. Clin Exp Immunol 2009; 157: 395-9.

15. Jensen ML, Honore C, Hummelshoj T, Hansen BE, Madsen HO, Garred P. Ficolin-2 recognizes DNA and participates in the clearance of dying host cells. Mol Immunol 2007; 44: 856-65.

16. Lynch NJ, Roscher S, Hartung T, et al. L-ficolin specifically binds to lipoteichoic acid, a cell wall constituent of Gram-positive bacteria, and activates the lectin pathway of complement. J Immunol 2004; 172: 1198-202.
17. Aoyagi Y, Adderson EE, Rubens CE, et al. L-Ficolin/mannosebinding lectin-associated serine protease complexes bind to group B streptococci primarily through $\mathrm{N}$-acetyl neuraminic acid of capsular polysaccharide and activate the complement pathway. Infect Immun 2008; 76: 179-88.

18. Munthe-Fog L, Hummelshoj T, Hansen BE, et al. The impact of FCN2 polymorphisms and haplotypes on the ficolin-2 serum levels. Scand J Immunol 2007; 65: 383-92.

19. Messias-Reason I, Kremsner PG, Kun JF. Functional haplotypes that produce normal ficolin-2 levels protect against clinical leprosy. J Infect Dis 2009; 199: 801-4.

20. Cedzynski M, Nuytinck L, Atkinson AP, et al. Extremes of L-ficolin concentration in children with recurrent infections are associated with single nucleotide polymorphisms in the FCN2 gene. Clin Exp Immunol 2007; 150: 99-104.

21. Hummelshoj T, Munthe-Fog L, Madsen HO, Fujita T, Matsushita M, Garred P. Polymorphisms in the FCN2 gene determine serum variation and function of ficolin-2. Hum Mol Genet 2005; 14: 1651-8.

22. Messias R, I, Schafranski MD, Jensenius JC, Steffensen R. The association between mannose-binding lectin gene polymorphism and rheumatic heart disease. Hum Immunol 2006; 67: 991-8.

23. Schafranski MD, Pereira FL, Scherner D, Torres R, Jensenius JC, Messias-Reason IJ. High-producing MBL2 genotypes increase the risk of acute and chronic carditis in patients with history of rheumatic fever. Mol Immunol 2008; 45: 3827-31.

24. Dajani AS, Ayoub E, Bierman FZ, et al. Guidelines for the diagnosis of rheumatic fever: Jones criteria, 1992 update. JAMA 1992; 268: 2069-73.

25. Rodriguez S, Gaunt TR, Day INM. Hardy-Weinberg equilibrium testing of biological ascertainment for mendelian randomization studies. Am J Epidemiol 2009; 169: 505-14.

26. Guilherme L, Kalil J. Rheumatic heart disease: molecules involved in valve tissue inflammation leading to the autoimmune process and anti-S. pyogenes vaccine. Front Immunol 2013; 4: 352.

27. Guilherme L, Kohler KF, Kalil J. Rheumatic heart disease: genes, inflammation and autoimmunity. Rheumatol Curr Res 2012; S4: 1-5.

28. Boldt ABW, Goeldner I, De Messias-Reason IJT. Relevance of the lectin pathway of complement in rheumatic diseases. Adv Clin Chem 2012; 56: 105-53.

29. Beltrame MH, Catarino SJ, Goeldner I, Boldt AB, de Messias-Reason IJ. The lectin pathway of complement and rheumatic heart disease. Front Pediatr 2015; 2: 148.

30. Atkinson AP, Cedzynski M, Szemraj J, et al. L-ficolin in children with recurrent respiratory infections. Clin Exp Immunol 2004; 138: 517-20.

31. Schoos MM, Munthe-Fog L, Skjoedt MO, et al. Association between lectin complement pathway initiators, C-reactive protein and left ventricular remodeling in myocardial infarction - a magnetic resonance study. Mol Immunol 2013; 54: 408-14.

32. Zehnder A, Fisch U, Hirt A, et al. Prognosis in pediatric hematologic malignancies is associated with serum concentration of mannose-binding lectin-associated serine protease-2 (MASP-2). Pediatr Blood Cancer 2009; 53: 53-7.

33. Marzetti V, Di Battista C, Ferrante R, et al. MBL2 and FCN2 gene polymorphisms in a cohort of Italian children with rheumatic fever: a case-control study. Semin Arthritis Rheum 2017; 47: 264-8. 
34. Pelajo C, Lopez-Benitez J, Torres J, de Oliveira S. Adherence to secondary prophylaxis and disease recurrence in 536 Brazilian children with rheumatic fever. Pediatr Rheumatol Online J 2010; 8: 22.

35. Ojurongbe O, Ouf EA, Van Tong H, et al. Reliable and rapid characterization of functional FCN2 gene variants reveals diverse geographical patterns. BMC Med Genet 2012; 13: 37.

36. Ferraroni NR, Segat L, Guimarães RL, et al. Mannosebinding lectin and MBL-associated serine protease-2 gene polymorphisms in a Brazilian population from Rio de Janeiro. Int J Immunogenet 2012; 39: 32-8.

37. Prohászka Z, Munthe-Fog L, Ueland T, et al. Association of ficolin-3 with severity and outcome of chronic heart failure. PLoS One 2013; 8: e60976.

38. Oliveira GH, Brann CN, Becker K, et al. Dynamic expression of the membrane attack complex (MAC) of the complement system in failing human myocardium. Am J Cardiol 2006; 97: 1626-9.

39. Shahini N, Michelsen AE, Nilsson PH, et al. The alternative complement pathway is dysregulated in patients with chronic heart failure. Sci Rep 2017; 7: 42532.

40. Paulus WJ, Tschöpe C. A novel paradigm for heart failure with preserved ejection fraction: comorbidities drive myocardial dysfunction and remodeling through coronary microvascular endothelial inflammation. J Am Coll Cardiol 2013; 62; 263-71.

41. Pavlov VI, La Bonte LR, Baldwin WM, Markiewski MM Lambris JD, Stahl GL. Absence of mannose-binding lectin prevents hyperglycemic cardiovascular complications. Am J Pathol 2012; 180: 104-12.

42. Xu LB, Zhou YF, Yao JL, et al. Apolipoprotein A1 polymorphisms and risk of coronary artery disease: a metaanalysis. Arch Med Sci 2017; 13: 813-9.

43. Mocumbi AO. Rheumatic heart disease in Africa: is there a role for genetic studies? Cardiovasc J Afr 2015; 26 (2 H3Africa Suppl): S21-6.

44. King CH, Fischler DF, Gerkin RD. Will genetic testing alter the management of disease caused by infectious agents? A cost-effectiveness analysis of gene-testing strategies for prevention of rheumatic fever. Clin Infect Dis 2002; 34: 1491-9. 